This is an author produced version of a paper published in Tree Genetics and Genomes.

This paper has been peer-reviewed but may not include the final publisher proof-corrections or pagination.

Citation for the published paper:

Henrik R. Hallingbäck and Gunnar Jansson. (2013) Genetic information from progeny trials: a comparison between progenies generated by open pollination and by controlled crosses. Tree Genetics and Genomes. Volume: 9, Number: 3, pp 731-740.

http://dx.doi.org/10.1007/s11295-012-0588-2.

Access to the published version may require journal subscription.

Published with permission from: Springer Verlag.

Standard set statement from the publisher:

The final publication is available at Springer via http://dx.doi.org/ 10.1007/s11295-0120588-2.

Epsilon Open Archive http://epsilon.slu.se 


\title{
Genetic information from progeny trials: a comparison between progenies generated by open pollination and by controlled crosses
}

\author{
Henrik R. Hallingbäck ${ }^{1, *}$ and Gunnar Jansson ${ }^{1,2}$ \\ ${ }^{1}$ Department of Plant Biology and Forest Genetics, Swedish University of Agricultural Sciences, PO Box 7080, \\ SE-750 07 Uppsala, Sweden, ${ }^{2}$ Skogforsk (The Forestry Research Institute of Sweden), Uppsala Science Park, \\ SE-751 83 Uppsala, Sweden
}

\begin{abstract}
When conifer progenies generated by open pollination are assessed in field tests, it is usually assumed that all progenies of the same mother are true half-sibs. This assumption may be invalid, leading to overestimation of additive genetic variation and heritability and to biased breeding values. From one Scots pine (Pinus sylvestris) and one Norway spruce (Picea abies) seed orchard, containing 28 and 36 parent clones respectively, progenies generated by open pollination (OP) and by controlled crosses (CC) were planted in adjacent trials at two to three sites in southern Sweden. The tree height and diameter at breast height were measured and genetic parameters based on these traits were estimated for OP and CC progenies separately, in order to enable comparisons. Narrow sense heritability estimates for Scots pine and Norway spruce OP progenies (in the ranges $0.04-0.13$ and $0.15-0.38$, respectively) did not differ significantly from CC estimates (0.07-0.12 and 0.23-0.30), suggesting that OP-based heritability values were not overestimated to any great extent. Similarly, genetic correlations between $\mathrm{OP}$ and $\mathrm{CC}$ progenies were in the ranges $0.87-0.88$ and $0.74-0.77$ for Scots pine and Norway spruce, respectively, being significantly lower than unity only in the case of Norway spruce. OP-based breeding values for both species should therefore correspond well with those predicted from CC progenies, albeit not perfectly for Norway spruce. In conclusion, the assumption of true half-sibs for OP progenies was not violated to the extent that genetic parameter estimates or breeding value predictions were seriously biased.
\end{abstract}

Keywords: Scots pine, Norway spruce, Coancestry, Genetic parameters, Open pollination, Controlled crossing

Notification: This article was published in Tree Genetics \& Genomes, June 2013, Volume 9, Issue 3, pp 731-740. The final publication is available at link.springer.com with the DOI $10.1007 / \mathrm{s} 11295-012-0588-2$.

* Corresponding author (e-mail: Henrik.Hallingback@slu.se)

\section{Introduction}

In conifer tree breeding, a common method to produce progeny trees in order to test parents is to use seed generated by open wind pollination. Although the fathers are unknown, genetic parameter estimation and breeding value prediction are still possible because the mother tree from which the progenies originated is known. Open pollination (OP) progenies are simple, time-saving and inexpensive to produce and are therefore often preferred to seed generated by controlled crossing (CC), for which both mother and father are known.

When using open pollination in order to estimate genetic parameters and the genetic gain achieved by selection, it is necessary to make certain assumptions. One of these assumptions is that all progeny of a maternal tree are pure half-sibs, resulting in an additive coancestry coefficient of 0.125 
(Falconer and Mackay, 1996). The reliability of this assumption has sometimes been challenged, since it requires that all progeny have different fathers (perfect panmixia) and that no offspring are produced by self pollination (Askew and El-Kassaby, 1994; Squillace, 1974). Violation of these requirements usually results in overestimation of both additive genetic variances and prediction of genetic selection gain. The danger of overestimation is due not solely to the higher than expected coancestry coefficient, but may also occur as a result of inbreeding depression and to confounding with dominance genetic variation (Borralho, 1994). Furthermore, breeding values predicted from progeny generated by open pollination may be biased because individual mothers may be pollinated by different sets of fathers which have different average breeding values. Differential and uneven paternal reproductive success in an open pollination situation may increase this bias further.

By genotyping OP generated progenies with molecular markers, a few studies on conifer species such as maritime pine (Pinus pinaster Ait.), Nordmann fir (Abies nordmanniana), red spruce (Picea rubens) and western larch (Larix occidentalis Nutt.) have determined the additive coancestry coefficient between progenies originating from a common mother; in some cases paternity assignment was also performed. Although substantial differences in paternal reproductive success were observed, the coancestry coefficient itself was not greatly affected (Doerksen and Herbinger, 2010; Gaspar et al., 2009; Hansen and Nielsen, 2010). In some of these studies, additive genetic variances and heritabilities were estimated utilising paternity information based on marker data, and were compared with estimates where the fathers were treated as unknown and progeny were consequently assumed to be true half-sibs (Doerksen and Herbinger, 2010; El-Kassaby et al., 2011; Hansen and Nielsen, 2010). It was shown that additive genetic variance estimates based on the half-sib assumption often differed considerably from estimates using paternity data but were not consistently larger. Given the limited number of parents studied, it was thus difficult to determine whether the differences were due to violation of assumption or to estimation error.

An alternative method of evaluating the reliability of OP progeny for the purpose of genetic pa- rameter estimation and breeding value prediction is the simultaneous establishments of trials with progenies generated by controlled crosses as well as by open pollination, preferably at the same site. Studies based on this type of comparison between the methods of progeny generation have hitherto been few in number, and most have used Eucalyptus spp (e.g. Costa e Silva et al., 2010; Griffin and Cotterill, 1987; Hodge et al., 1996). To our knowledge there are no published studies on conifers comparing genetic parameters estimated from OP and CC progenies of the same parents.

The main objective of this study was to investigate whether genetic parameters for Scots pine $(P i$ nus sylvestris L.) and Norway spruce (Picea abies L. Karst.) estimated from progenies generated by controlled crosses and by open pollination were different. The study was also aimed at evaluating the correspondence of parental breeding values predicted from open pollination trials with those predicted from trials generated by controlled crosses. This investigation was possible because the same set of parents was used for the simultaneouslyestablished progeny trials generated both by controlled crosses and by open pollination. Genetic correlations between trials using these both crossing designs could thus be estimated.

\section{Materials and methods}

\section{Field material and measurements}

Two grafted seed orchards with scions from 36 Norway spruce and 28 Scots pine plus trees were established during the years 1956-1962. The Norway spruce seed orchard was established in Maglehem (lat. $55.77^{\circ} \mathrm{N}$, long. $14.17^{\circ} \mathrm{E}$, alt. $30 \mathrm{~m} \mathrm{a} \mathrm{sl}$ ) and the Scots pine seed orchard in Harastorp (lat. $56.00^{\circ} \mathrm{N}$, long. $13.87^{\circ} \mathrm{E}$, alt. $100 \mathrm{~m} \mathrm{a} \mathrm{sl}$ ). The plus trees were represented by equal numbers of grafts in both seed orchards. Approximately half (15) of the Scots pine plus trees were selected in north German stands (lat. $50.47^{\circ} \mathrm{N}-54.12^{\circ} \mathrm{N}$ ), while the rest of the Scots pine and all the Norway spruce plus trees were selected from south Swedish stands (lat. $55.87^{\circ} \mathrm{N}-56.32^{\circ} \mathrm{N}$ and $56.05^{\circ} \mathrm{N}-58.48^{\circ} \mathrm{N}$, respectively). For both species, phenotypic plus tree selection was performed based on vigour, height, diameter, straightness, and proportion of branches 
with small diameters and horizontal growth.

When the seed orchards were 15-20 years old, progenies for Scots pine and Norway spruce trials were generated by controlled full-sib crosses between parent plus trees, and also by open pollination of the same parent plus trees. The controlled crossing was performed according to a circulant partial diallel mating design in which each Scots pine and Norway spruce parent was represented in six and seven crosses respectively (Kempthorne and Curnow, 1961). The offspring seed generated by open pollination was harvested during one single year. Progeny trial seedlings (2-year-old for Scots pine and 3-year-old for Norway spruce) were established at three sites for Norway spruce and two sites for Scots pine. All sites were located in southern Sweden (Lönsboda, Tönnersjö and Vetlanda; Table 1).

Progenies from controlled crosses and from open pollination were planted at each site simultaneously, but in separate trials located very close to each other. The progenies were randomised in single-tree plots, with each open pollinated half-sib family and each controlled cross full-sib family represented at least twice in each block. The spacing was $1.8 \times 1.8 \mathrm{~m}$ for the Scots pine seedlings and 2 $\times 2 \mathrm{~m}$ for Norway spruce.

After 10-12 years in the field, height growth (H1) was assessed in all progeny trials and diameter at breast height (D1) was measured in the Scots pine trials (Table 1). For the Norway spruce trials, diameter at breast height was measured after 28-29 years in the field (D2).

\section{Estimation of variance components}

Estimation of variance and covariance components was carried out using restricted maximum likelihood implemented in ASReml (Gilmour et al., 2009). Checklot trees were consistently excluded from the analysis. Each species and trait was analysed separately, but data from all available CC and OP progenies from all sites were analysed simultaneously. This was done by using multivariate models where, for example, height measurements from different sites and crossing designs (CC or OP) were treated as separate traits (Burdon, 1977), using the following model:

$$
\mathbf{y}=\mathbf{X}_{\mathbf{b}} \mathbf{b}+\mathbf{Z}_{\mathrm{g}} \mathbf{g}+\mathbf{Z}_{\mathbf{f}} \mathbf{f}+\mathbf{e}
$$

where $\mathbf{y}=\left[\mathbf{y}^{\prime}{ }_{1} \ldots \mathbf{y}^{\prime}{ }_{2 s}\right]^{\prime}$ is the trait observation vector and the vectors $\mathbf{b}=\left[\mathbf{b}_{1}^{\prime} \ldots \mathbf{b}_{2 s}^{\prime}\right]^{\prime}, \mathbf{g}=$ $\left[\mathbf{g}^{\prime}{ }_{1} \ldots \mathbf{g}^{\prime}{ }_{2 s}\right]^{\prime}, \mathbf{f}=\left[\mathbf{f}^{\prime}{ }_{1} \ldots \mathbf{f}^{\prime}{ }_{2 s}\right]^{\prime}$ and $\mathbf{e}=\left[\mathbf{e}^{\prime}{ }_{1} \ldots \mathbf{e}^{\prime}{ }_{2 s}\right]^{\prime}$ represent the fixed block effects, random individual additive genetic effects, random full-sib family effects and residuals partitioned into subvectors for the investigated trials 1 to $2 s$, where $s$ is the number of sites. The output was arranged so that predicted effects from CC trials were located in the upper half of each vector ( 1 to $s$ ) while effects from OP trials were located in the lower half $(s+1$ to $2 s)$. The design matrices $\mathbf{X}_{\mathbf{b}}, \mathbf{Z}_{\mathbf{g}}$ and $\mathbf{Z}_{\mathbf{f}}$ relate observations to block, individual additive genetic and specific full-sib family effects respectively. Provenance effects between north German and south Swedish Scots pine parents were not included in the model because initial analyses indicated that such effects were negligible.

All random effects were assumed to be independently and normally distributed with expected values of zero and structured as:

$$
\operatorname{Var}\left[\begin{array}{c}
\mathbf{g} \\
\mathbf{f} \\
\mathbf{e}
\end{array}\right]=\left[\begin{array}{ccc}
\mathbf{G} \otimes \mathbf{A} & \mathbf{0} & \mathbf{0} \\
\mathbf{0} & \mathbf{F} \otimes \mathbf{I}_{\mathbf{f}} & \mathbf{0} \\
\mathbf{0} & \mathbf{0} & \mathbf{R} \otimes \mathbf{I}_{\mathbf{e}}
\end{array}\right]
$$

where $\mathbf{G}, \mathbf{F}$ and $\mathbf{R}$ are additive genetic, full-sib family and residual variance-covariance matrices, respectively, each having a dimension of $2 s \times 2 s$. $\mathbf{A}$ is the individual additive genetic coancestry matrix while $\mathbf{I}_{\mathbf{f}}$ and $\mathbf{I}_{\mathbf{e}}$ are identity matrices associated with the full-sib family and residual variancecovariance matrices respectively. All variances and covariances in $\mathbf{F}$ pertaining to the OP trials and corresponding parts of the full-sib family effects $\left(\left[\mathbf{f}^{\prime}{ }_{s+1} \ldots \mathbf{f}^{\prime}{ }_{2 s}\right]^{\prime}\right)$ were preset at zero. Consequently all OP generated progenies with the same mother were assumed to be true half-sibs implying a coancestry cofficient of 0.125 (equivalent to an intraclass-correlation coefficient of 0.25 ) between individuals (Falconer and Mackay, 1996; Squillace, 1974). As measurements from each trial were always considered to be separate traits, there was no information available to estimate residual covariances between them and $\mathbf{R}$ was therefore structured as a diagonal variance-covariance matrix. 
Table 1: Description of the progeny trials used in this study

\begin{tabular}{|c|c|c|c|c|c|c|c|c|c|c|}
\hline \multirow{5}{*}{$\begin{array}{l}\text { Site } \\
\text { Latitude } \\
\text { Longitude } \\
\text { Altitude (m a sl) }\end{array}$} & \multicolumn{4}{|c|}{ Scots pine } & \multicolumn{6}{|c|}{ Norway spruce } \\
\hline & \multicolumn{2}{|c|}{ Lönsboda } & \multicolumn{2}{|c|}{ Tönnersjö } & \multicolumn{2}{|c|}{ Lönsboda } & \multicolumn{2}{|c|}{ Tönnersjö } & \multicolumn{2}{|c|}{ Vetlanda } \\
\hline & \multicolumn{2}{|c|}{$56.43^{\circ} \mathrm{N}$} & \multicolumn{2}{|c|}{$56.63^{\circ} \mathrm{N}$} & \multicolumn{2}{|c|}{$56.43^{\circ} \mathrm{N}$} & \multicolumn{2}{|c|}{$56.66^{\circ} \mathrm{N}$} & \multicolumn{2}{|c|}{$57.41^{\circ} \mathrm{N}$} \\
\hline & \multicolumn{2}{|c|}{$14.32^{\circ} \mathrm{E}$} & \multicolumn{2}{|c|}{$13.07^{\circ} \mathrm{E}$} & \multicolumn{2}{|c|}{$14.33^{\circ} \mathrm{E}$} & \multicolumn{2}{|c|}{$13.09^{\circ} \mathrm{E}$} & \multicolumn{2}{|c|}{$15.15^{\circ} \mathrm{E}$} \\
\hline & \multicolumn{2}{|c|}{150} & \multicolumn{2}{|c|}{55} & \multicolumn{2}{|c|}{150} & \multicolumn{2}{|c|}{90} & \multicolumn{2}{|c|}{230} \\
\hline Crossing type $^{a}$ & $\mathrm{CC}$ & $\mathrm{OP}$ & $\mathrm{CC}$ & $\mathrm{OP}$ & $\mathrm{CC}$ & $\mathrm{OP}$ & $\mathrm{CC}$ & $\mathrm{OP}$ & $\mathrm{CC}$ & $\mathrm{OP}$ \\
\hline No of blocks & 16 & 8 & 12 & 8 & 10 & 10 & 10 & 10 & 10 & 10 \\
\hline No of parents & 28 & 24 & 28 & 24 & 36 & 36 & 36 & 36 & 36 & 36 \\
\hline No of crosses & 83 & - & 84 & - & 88 & - & 115 & - & 106 & - \\
\hline No of replicates ${ }^{b}$ & 40 & 60 & 40 & 60 & 40 & 40 & 40 & 40 & 40 & 40 \\
\hline Traits measured $^{c}$ & \multicolumn{2}{|c|}{ H1,D1 } & \multicolumn{2}{|c|}{$\mathrm{H} 1, \mathrm{D} 1$} & \multicolumn{2}{|c|}{$\mathrm{H} 1, \mathrm{D} 2$} & \multicolumn{2}{|c|}{ H1,D2 } & \multicolumn{2}{|c|}{ H1,D2 } \\
\hline
\end{tabular}

\section{Interpretation of variance compo- nents}

Estimates of additive genetic variances $\left(\hat{\sigma}_{A i}^{2}\right)$ and covariances $\left(\hat{\sigma}_{A i j}\right)$ for progeny trials $i$ and $j$ were obtained directly from the estimated $\mathbf{G}$ variancecovariance matrix (Equation 2). Dominance variance estimates $\left(\hat{\sigma}_{D i}^{2}\right)$ from each CC trial $i$ were calculated by multiplying the respective full-sib family $\left(\hat{\sigma}_{f i}^{2}\right)$ variance components (obtained from $\mathbf{F}$ ) by 4. The estimation of phenotypic variances for each trial $\left(\hat{\sigma}_{P i}^{2}\right)$ was performed in two different ways depending on whether the trial $i$ had a CC or OP crossing design:

$$
\begin{gathered}
\mathrm{CC}: \hat{\sigma}_{P i}^{2}=\hat{\sigma}_{A i}^{2}+\hat{\sigma}_{f i}^{2}+\hat{\sigma}_{e i}^{2} \\
\mathrm{OP}: \hat{\sigma}_{P i}^{2}=\hat{\sigma}_{A i}^{2}+\hat{\sigma}_{e i}^{2}
\end{gathered}
$$

where $\hat{\sigma}_{e i}^{2}$ is the residual variance estimate from trial $i$ extracted from $\mathbf{R}$. Based on these genetic variances and covariances and on the trait mean of trial $i\left(\hat{\mu}_{i}\right)$, the narrow-sense heritability $\left(\hat{h}_{i}^{2}\right)$, the dominance ratio $\left(\hat{d}_{i}^{2}\right)$ and the percentage coefficient of additive genetic variation $\left(\hat{C V} \hat{A}_{A i}\right)$ were calculated as:

$$
\hat{h}_{i}^{2}=\frac{\hat{\sigma}_{A i}^{2}}{\hat{\sigma}_{P i}^{2}} \quad \hat{d}_{i}^{2}=\frac{\hat{\sigma}_{D i}^{2}}{\hat{\sigma}_{P i}^{2}} \quad \hat{C V} V_{A i}=100 \frac{\hat{\sigma}_{A i}}{\hat{\mu}_{i}}
$$

\section{Estimation and interpretation of ge- netic correlations}

To evaluate the correspondence between the predicted breeding values for any pair of trials $i$ and $j$, additive genetic correlations $\left(\hat{r}_{A i j}\right)$ were calculated from estimated variance-covariance components of $\mathbf{G}$ as:

$$
\hat{r}_{A i j}=\frac{\hat{\sigma}_{A i j}}{\hat{\sigma}_{A i} \hat{\sigma}_{A j}}
$$

Although the additive genetic correlations $\left(\hat{r}_{A i j}\right)$ between any $\mathrm{CC}$ and $\mathrm{OP}$ trials could be regarded as an estimate of $\mathrm{CC}-\mathrm{OP}$ breeding value correspondence, such an interpretation may be biased downwards because of confounding with $\mathrm{G} \times \mathrm{E}$ interactions. Such confounding could obviously occur when correlations between a $\mathrm{CC}$ trial at one site and an OP trial at another site are considered. However, similar confounding is also conceivable in the case of CC and OP progenies at the same site, because $\mathrm{CC}$ and $\mathrm{OP}$ progenies were separated in two trials. To account for these potential sources of bias, additional analyses were carried out in which all additive genetic correlations were categorized into three groups: i) additive genetic correlations between sites but within each crossing design $\left(r_{a}\right)$; ii) additive genetic correlations between crossing designs but within each site $\left(r_{b}\right)$; and iii) additive genetic correlations between crossing designs and across sites $\left(r_{c}\right)$. The additive genetic correlations within each group were constrained to be equal. 
Taking the analysis of one of the traits measured in Scots pine as an example, these constraints are described by the following upper triangular correlation matrix:

$$
\left[\begin{array}{cccc}
1 & r_{A 12} & r_{A 13} & r_{A 14} \\
& 1 & r_{A 23} & r_{A 24} \\
& & 1 & r_{A 34} \\
& & & 1
\end{array}\right]=\left[\begin{array}{cccc}
1 & r_{a} & r_{b} & r_{c} \\
& 1 & r_{c} & r_{b} \\
& & 1 & r_{a} \\
& & & 1
\end{array}\right]
$$

CC trials are represented by subscript indices 1 and 2 and OP trials are represented by indices 3 and 4. The first site (Lönsboda) is represented by the odd indices while the other site (Tönnersjö) is represented by the even indices. The constrained additive genetic correlations were considered to be products of several correlations described as:

$$
\begin{array}{ll}
\text { a) }: & \hat{r}_{a}=\hat{r}_{S} \cdot \hat{r}_{S T} \\
\text { b) }: & \hat{r}_{b}=\hat{r}_{T} \cdot \hat{r}_{S T} \\
\text { c) }: & \hat{r}_{c}=\hat{r}_{T} \cdot \hat{r}_{S} \cdot \hat{r}_{S T}
\end{array}
$$

where $\hat{r}_{S}$ is the additive genetic correlation across sites $(\mathrm{S}), \hat{r}_{T}$ is the additive genetic correlation between CC and OP crossing designs (T) and $\hat{r}_{S T}$ is the additive genetic correlation between trials within each site $(\mathrm{S} \times \mathrm{T})$. This interpretation resembles a univariate multisite analysis where trials are considered to be hierarchically nested within sites. Then $\hat{r}_{T}, \hat{r}_{S}$ and $\hat{r}_{S T}$ can be calculated as:

$$
\hat{r}_{T}=\frac{\hat{r}_{c}}{\hat{r}_{a}} \quad \hat{r}_{S}=\frac{\hat{r}_{c}}{\hat{r}_{b}} \quad \hat{r}_{S T}=\frac{\hat{r}_{a} \cdot \hat{r}_{b}}{\hat{r}_{c}}
$$

The additive genetic correlation $\hat{r}_{T}$ is thus considered to reflect the correspondence in breeding values between $\mathrm{CC}$ and OP trials in an unbiased manner, while $\hat{r}_{S} \cdot \hat{r}_{S T}$ is considered to reflect exclusively the correspondence in breeding values across environments (non-correspondence indicating $\mathrm{G} \times \mathrm{E}$ interactions). The assumption that $\hat{r}_{S T}$ exclusively reflects the correspondence in breeding values across environments is reasonable because short range $\mathrm{G} \times \mathrm{E}$ interactions within each site would not be reproduced across sites, thus producing $\hat{r}_{S T}$ estimates that were less than one. In contrast, the lack of correspondence between CC and OP crossing designs, caused by deviations from random mating and panmixia in the parental seed orchard, would be consistent across sites and would therefore be unlikely to affect $\hat{r}_{S T}$.

\section{Estimation errors and parameter sig- nificance tests}

The standard errors of genetic parameters were estimated by ASReml (Gilmour et al., 2009) using the Taylor series expansion. To determine whether narrow-sense heritabilities of OP trials were significantly different from the corresponding CC trial heritabilities, additional analyses were performed constraining the $\mathrm{CC}$ and $\mathrm{OP}$ heritabilities at any chosen site to be equal $(M O)$. The significance of heritability differences was then determined by comparing the log-likelihood value of the constrained analysis $\left(\lambda_{M 0}\right)$ with the corresponding value of the non-constrained analysis $\left(\lambda_{M x}\right)$. The log-likelihood ratio $\left(-2\left(\lambda_{M x}-\lambda_{M 0}\right)\right)$ was tested against the $\chi_{d f=1}^{2}$ distribution (log-likelihood ratio test) where the number of degrees of freedom $(d f)$ was given by the difference in the number of estimated parameters between non-constrained $(M x)$ and constrained $(M O)$ analyses.

In the same manner we determined whether the additive genetic correlation factors $\hat{r}_{T}$ and $\hat{r}_{S}$ were significantly lower than unity by imposing the additional respective constraints $\hat{r}_{a}=\hat{r}_{c}$ or $\hat{r}_{b}=\hat{r}_{c}$ in log-likelihood ratio tests against the $\chi_{1}^{2}$ distribution. We also determined whether the individual additive genetic correlation estimates $\left(\hat{r}_{A i j}\right)$ and constrained additive genetic correlation estimates $\left(\hat{r}_{a}, \hat{r}_{b}\right.$ and $\left.\hat{r}_{c}\right)$ were significantly lower than one by constraining each of these correlations to unity. In the case of log-likelihood ratio testing genetic correlations at unity, a 50:50 mix of $\chi_{1}^{2}$ and $\chi_{0}^{2}$ distributions was used in accordance with the method for testing null-hypotheses of parameters at their outer boundaries (Jordan et al., 1999; Self and Liang, 1987).

\section{Results}

\section{Progeny trial trait means}

The trial averages for tree height at age 10-12 years (H1) were in the range 3.1-4.3 $\mathrm{m}$ for both Norway spruce and Scots pine, while the diameter averages for Scots pine at the same age (D1) were 5.0-6.1 $\mathrm{cm}$ (Table 2). Trial averages for diameter at breast height at age 28-29 years for Norway spruce were in the range $13.2-14.4 \mathrm{~cm}$. For Scots pine, OP trait means were reduced by $2 \%-11 \%$ in compar- 
Table 2: Number of observations, mean, additive genetic variance $\left(\hat{\sigma}_{A}^{2}\right)$, residual variance $\left(\hat{\sigma}_{e}^{2}\right)$, additive genetic coefficients of variation $\left(\hat{C V} V_{A}\right)$, heritability $\left(\hat{h}^{2}\right)$, and dominance ratio $\left(\hat{d}^{2}\right)$ estimated for height growth at age 10-12 years (H1) and diameter at breast height at ages 10-12 years (D1) and 28-29 years (D2) assessed at different trials generated by controlled crosses (CC) or by open pollination (OP)

\begin{tabular}{|c|c|c|c|c|c|c|c|c|}
\hline Trait & $\begin{array}{l}\text { Crossing } \\
\text { design }\end{array}$ & $\begin{array}{l}\text { No of } \\
\text { trees }\end{array}$ & $\begin{array}{l}\text { Trait } \\
\text { mean }\end{array}$ & $\hat{\sigma}_{A}^{2}$ & $\hat{\sigma}_{e}^{2}$ & $\begin{array}{l}\hat{C V_{A}} \\
(\%)\end{array}$ & $\hat{h}^{2}$ & $\hat{d}^{2}$ \\
\hline \multicolumn{9}{|c|}{ Scots pine } \\
\hline \multicolumn{9}{|c|}{ Lönsboda } \\
\hline H1 & $\mathrm{CC}$ & 2403 & $3.8 \mathrm{~m}$ & $0.04(0.02)$ & $0.61(0.02)$ & $5.4(2.3)$ & $0.07(0.03)$ & $0.06(0.04)$ \\
\hline $\mathrm{H} 1$ & $\mathrm{OP}$ & 1245 & $3.7 \mathrm{~m}$ & $0.09(0.04)$ & $0.61(0.04)$ & $8.3(3.8)$ & $0.13(0.06)$ & - \\
\hline D1 & $\mathrm{CC}$ & 2384 & $5.5 \mathrm{~cm}$ & $0.3(0.1)$ & $2.7(0.1)$ & $9.4(3.6)$ & $0.09(0.03)$ & $0.06(0.04)$ \\
\hline D1 & $\mathrm{OP}$ & 1230 & $5.0 \mathrm{~cm}$ & $0.4(0.2)$ & $2.4(0.1)$ & $12.2(5.6)$ & $0.13(0.06)$ & - \\
\hline \multicolumn{9}{|c|}{ Tönnersjö } \\
\hline H1 & $\mathrm{CC}$ & 2892 & $3.8 \mathrm{~m}$ & $0.05(0.02)$ & $0.34(0.01)$ & $5.6(2.1)$ & $0.12(0.04)$ & $0.09(0.04)$ \\
\hline $\mathrm{H} 1$ & $\mathrm{OP}$ & 1295 & $3.6 \mathrm{~m}$ & $0.04(0.02)$ & $0.31(0.02)$ & $5.3(2.6)$ & $0.11(0.05)$ & - \\
\hline D1 & $\mathrm{CC}$ & 2892 & $6.1 \mathrm{~cm}$ & $0.2(0.1)$ & $2.4(0.1)$ & $6.9(2.9)$ & $0.07(0.03)$ & $0.07(0.03)$ \\
\hline D1 & $\mathrm{OP}$ & 1294 & $5.7 \mathrm{~cm}$ & $0.1(0.1)$ & $2.3(0.1)$ & $5.7(4.5)$ & $0.04(0.03)$ & - \\
\hline \multicolumn{9}{|c|}{ Norway spruce } \\
\hline H1 & $\mathrm{CC}$ & 3019 & $3.5 \mathrm{~m}$ & $0.41(0.11)$ & $1.04(0.07)$ & $18.6(5.1)$ & $0.28(0.07)$ & $0.05(0.03)$ \\
\hline H1 & $\mathrm{OP}$ & 1359 & $4.3 \mathrm{~m}$ & $0.36(0.12)$ & $0.91(0.10)$ & $13.9(4.5)$ & $0.28(0.09)$ & - \\
\hline D2 & $\mathrm{CC}$ & 2717 & $13.2 \mathrm{~cm}$ & $7.7(2.1)$ & $17.3(1.2)$ & $20.9(5.8)$ & $0.30(0.07)$ & $0.06(0.03)$ \\
\hline D2 & $\mathrm{OP}$ & 1334 & $13.4 \mathrm{~cm}$ & $6.9(2.1)$ & $13.1(1.8)$ & $19.5(6.0)$ & $0.34(0.10)$ & - \\
\hline \multicolumn{9}{|c|}{ Tönnersjö } \\
\hline $\mathrm{H} 1$ & $\mathrm{CC}$ & 3765 & $3.9 \mathrm{~m}$ & $0.20(0.05)$ & $0.63(0.03)$ & $11.2(3.1)$ & $0.23(0.06)$ & $0.09(0.03)$ \\
\hline H1 & $\mathrm{OP}$ & 1247 & $3.1 \mathrm{~m}$ & $0.25(0.08)$ & $0.41(0.06)$ & $16.4(5.0)$ & $0.38(0.11)$ & - \\
\hline D2 & $\mathrm{CC}$ & 3450 & $14.4 \mathrm{~cm}$ & $3.6(1.0)$ & $9.2(0.6)$ & $13.3(3.5)$ & $0.28(0.06)$ & $0.03(0.02)$ \\
\hline D2 & $\mathrm{OP}$ & 1073 & $13.2 \mathrm{~cm}$ & $2.7(0.9)$ & $7.1(0.8)$ & $12.3(4.3)$ & $0.27(0.09)$ & - \\
\hline \multicolumn{9}{|c|}{ Vetlanda } \\
\hline $\mathrm{H} 1$ & $\mathrm{CC}$ & 3804 & $3.4 \mathrm{~m}$ & $0.17(0.05)$ & $0.50(0.03)$ & $12.1(3.4)$ & $0.24(0.06)$ & $0.11(0.03)$ \\
\hline H1 & $\mathrm{OP}$ & 1374 & $3.8 \mathrm{~m}$ & $0.09(0.04)$ & $0.55(0.04)$ & $8.1(3.3)$ & $0.15(0.06)$ & - \\
\hline D2 & $\mathrm{CC}$ & 3725 & $13.7 \mathrm{~cm}$ & $5.2(1.4)$ & $11.7(0.8)$ & $16.6(4.4)$ & $0.30(0.07)$ & $0.04(0.02)$ \\
\hline D2 & $\mathrm{OP}$ & 1356 & $14.0 \mathrm{~cm}$ & $3.4(1.2)$ & $12.2(1.1)$ & $13.1(4.6)$ & $0.21(0.07)$ & - \\
\hline
\end{tabular}

Note: Standard errors are given in parentheses. None of the $\hat{h}^{2}$ estimates from OP trials were significantly different from their respective estimates from $\mathrm{CC}$ trials $(p \geq 0.05)$ 
ison with $\mathrm{CC}$ averages and thus trees in $\mathrm{OP}$ trials showed a slight tendency to grow more slowly while Norway spruce OP trait averages were between $21 \%$ smaller and 23\% larger than the corresponding CC trait averages. The average growth of the checklots was consistent with these patterns suggesting that environmental factors were the primary source of the observed differences. Tree survival was $72 \%$ and higher in the Scots pine trials and $82 \%$ and higher in the Norway spruce trials.

\section{Genetic coefficient of variation and heritability}

In all Scots pine progeny trials, the estimates of both additive genetic coefficient of variation $\left(\hat{C V} V_{A}\right)$ and heritability $(5 \%-12 \%$ and $0.04-0.13$ respectively) were low (Table 2), and their respective standard errors were considerable $(2 \%-6 \%$ and 0.03-0.06) compared with the estimates. However, the Norway spruce trials exhibited higher $\hat{C V} A_{A^{-}}$ values $(8 \%-21 \%)$ and higher heritability estimates (0.15-0.38), though the standard errors of these parameters $(3 \%-6 \%$ and $0.06-0.11)$ were similar to those of Scots pine.

$\hat{C V}{ }_{A}$ and heritabilities estimated from $\mathrm{OP}$ trials varied considerably when compared with the corresponding estimates from CC trials for both species (Table 2); they could be either substantially smaller or substantially larger than the CC estimates. The differences between $\mathrm{OP}$ and $\mathrm{CC}$ estimates were therefore not systematic, and moreover $\mathrm{OP}$ and $\mathrm{CC}$ estimates of heritability were never significantly different from each other at the 0.05 level. On average, Scots pine OP trials exhibited heritability estimates $29 \%$ larger than those from CC trials while the estimates from Norway spruce $\mathrm{OP}$ were on average only $1 \%$ larger than the corresponding averages from CC trials. The traits investigated (H1, D1 and D2) did not differ appreciably with respect to heritability or $\hat{C V}{ }_{A}$ estimates. Dominance ratio estimates $\left(\hat{d}^{2}\right)$ in the CC trials were consistently low (0.03-0.11) for both species and their estimation errors were considerable $(0.02-$ $0.09)$.

\section{Genetic correlations between progeny trials}

Additive genetic correlation estimates $\left(\hat{r}_{A}\right)$ between $\mathrm{CC}$ and OP progeny trials of Scots pine (Table 3 ) had an average value of 0.91 , were distributed across a wide range (0.41-1.09), and had relatively large standard errors (in the range $0.14-0.32$ ); only two out of eight CC-OP correlation estimates (CC Lon - OP Ton for both traits) were significantly lower than unity. Additive genetic correlations estimated across sites and trials (environments) but within crossing design were on average 0.93 , falling in the range $0.77-1.04$, and only one of these values was significantly lower than unity. Additive CCOP genetic correlation estimates for Norway spruce (Table 4) had an average value of 0.65 , falling in the range $0.44-0.80$, and all (18) were significantly lower than one. Standard errors of the CC-OP genetic correlations were in the range $0.12-0.18$ and generally smaller than the corresponding errors observed for Scots pine. Norway spruce genetic correlations estimated within crossing type but across environments were on average 0.83 , within the range $0.63-1.02$, and eight out of the twelve values were significantly lower than unity, suggesting $\mathrm{G} \times \mathrm{E}$ interactions. The traits studied did not show any appreciable differences in terms of additive genetic correlation estimates in either species.

\section{Genetic correlations between crossing designs and environments}

By categorising the genetic correlations into groups with respect to the relationship between each pair of variates studied and by constraining the correlation estimates within these groups to be equal (Equation 3), overall estimates for the data across all sites could be obtained (Table 5). It was also possible to obtain OP-CC genetic correlations adjusted for the potential effects of $\mathrm{G} \times \mathrm{E}$ interactions (Equation 4). In Scots pine, none of the adjusted genetic correlations between $\mathrm{OP}$ and $\mathrm{CC}$ crossing designs $\left(\hat{r}_{T}\right)$ were significantly lower than unity $(0.87-0.88)$ and they were within the range of the genetic correlations unadjusted for the effect of the $\mathrm{G} \times \mathrm{E}$ interactions $\left(\hat{r}_{b}\right.$ and $\hat{r}_{c}$ in the range 0.73-1.06). Genetic correlations estimated across environments $\left(\hat{r}_{a}\right)$ were in the range $0.83-0.95$ and only one of them was significantly lower than unity. 
Table 3: Additive genetic correlations $\left(\hat{r}_{A}\right)$ between individual Scots pine controlled cross (CC) and open pollination (OP) trials located at Lönsboda (Lon) and Tönnersjö (Ton) estimated for height (H1, upper diagonal) and diameter at breast height (D1, lower diagonal)

\begin{tabular}{lccccc}
\hline \multirow{2}{*}{ Sites } & \multicolumn{2}{c}{ Controlled crosses } & & \multicolumn{2}{c}{ Open pollination } \\
\cline { 2 - 3 } \cline { 5 - 6 } \cline { 5 - 6 } CC Lon & Lon & Ton & & Lon & Ton \\
CC Ton & $\mathbf{0 . 7 7}(\mathbf{0 . 1 6})$ & - & & $0.98(0.14)$ & $1.00(0.15)$ \\
OP Lon & $1.09(0.14)$ & $0.99(0.16)$ & & - & $1.01(0.18)$ \\
OP Ton & $\mathbf{0 . 4 1}(\mathbf{0 . 3 8})$ & $1.05(0.33)$ & & $1.04(0.32)$ & - \\
\hline
\end{tabular}

Note: Standard errors are given in parentheses and correlation estimates significantly lower than unity $(p<0.05)$ are given in bold.

Table 4: Additive genetic correlations $\left(\hat{r}_{A}\right)$ between individual Norway spruce controlled cross (CC) and open pollination (OP) trials located at Lönsboda (Lon), Tönnersjö (Ton) and Vetlanda (Vet) estimated for height (H1, upper diagonal) and diameter at breast height (D2, lower diagonal)

\begin{tabular}{lcccccccc}
\hline & \multicolumn{3}{c}{ Controlled crosses } & & \multicolumn{3}{c}{ Open pollination } \\
\cline { 2 - 4 } \cline { 6 - 8 } Sites & Lon & Ton & Vet & & Lon & Ton & Vet \\
CC Lon & - & $\mathbf{0 . 8 7}(\mathbf{0 . 0 7})$ & $\mathbf{0 . 8 1}(\mathbf{0 . 0 8})$ & & $\mathbf{0 . 6 3}(\mathbf{0 . 1 6})$ & $\mathbf{0 . 5 2}(\mathbf{0 . 1 6})$ & $\mathbf{0 . 6 3}(\mathbf{0 . 1 8})$ \\
CC Ton & $\mathbf{0 . 7 1}(\mathbf{0 . 1 0})$ & - & $\mathbf{0 . 9 2}(\mathbf{0 . 0 5})$ & & $\mathbf{0 . 6 0}(\mathbf{0 . 1 6})$ & $\mathbf{0 . 7 2}(\mathbf{0 . 1 2})$ & $\mathbf{0 . 6 3}(\mathbf{0 . 1 8})$ \\
CC Vet & $\mathbf{0 . 8 7}(\mathbf{0 . 0 6})$ & $\mathbf{0 . 8 7}(\mathbf{0 . 0 6})$ & - & & $\mathbf{0 . 6 8}(\mathbf{0 . 1 4})$ & $\mathbf{0 . 5 9}(\mathbf{0 . 1 5})$ & $\mathbf{0 . 6 3}(\mathbf{0 . 1 8})$ \\
OP Lon & $\mathbf{0 . 6 5}(\mathbf{0 . 1 4})$ & $\mathbf{0 . 4 4}(\mathbf{0 . 1 7})$ & $\mathbf{0 . 6 6}(\mathbf{0 . 1 3})$ & & - & $\mathbf{0 . 6 3}(\mathbf{0 . 1 6})$ & $0.84(0.16)$ \\
OP Ton & $\mathbf{0 . 8 0}(\mathbf{0 . 1 2})$ & $\mathbf{0 . 7 8}(\mathbf{0 . 1 2})$ & $\mathbf{0 . 7 5}(\mathbf{0 . 1 3})$ & & $\mathbf{0 . 6 2}(\mathbf{0 . 1 7})$ & - & $0.86(0.14)$ \\
OP Vet & $\mathbf{0 . 6 6}(\mathbf{0 . 1 5})$ & $\mathbf{0 . 5 6}(\mathbf{0 . 1 7})$ & $\mathbf{0 . 7 5}(\mathbf{0 . 1 3})$ & & $1.02(0.09)$ & $0.91(0.13)$ & -
\end{tabular}

Note: Standard errors are given in parentheses and correlation estimates significantly lower than unity $(p<0.05)$ are given in bold. 
For Norway spruce, the adjusted OP-CC genetic correlation estimates $\left(\hat{r}_{T}\right)$ were also high (0.74$0.77)$, but lower than those for Scots pine, and all were significantly lower than unity (Table 5). The corresponding OP-CC genetic correlations unadjusted for the effects of $\mathrm{G} \times \mathrm{E}$ interactions $\left(\hat{r}_{b}\right.$ and $\hat{r}_{c}$ ) were slightly lower (in the range $0.61-0.72$ ) than the $\hat{r}_{T}$ values, suggesting that $\mathrm{G} \times \mathrm{E}$ interactions may have biased the former estimates. The genetic correlations estimated across sites and trials $\left(\hat{r}_{a}\right)$ were both 0.83 and significantly lower than unity, indicating the presence of $\mathrm{G} \times \mathrm{E}$ interactions. Thus, both crossing design and environment were found to interact significantly with genotype in the case of Norway spruce; however, because the estimates were high, the extent of the interactions appeared to be limited.

\section{Discussion}

Doubts have been expressed as to whether the assumption of true half-sibs is reasonable for progenies generated by open pollination (Askew and El-Kassaby, 1994; Borralho, 1994; Squillace, 1974). However, there are few reports of studies using experimental data to prove or refute the validity of this assumption with respect to the estimation of genetic parameters.

The genetic material in this study was restricted to 28 Scots pine and 36 Norway spruce parents, and this imposes certain limits on the precision of genetic parameter estimates. In addition, the separate establishment of $\mathrm{CC}$ and of OP progeny at each site introduced the problem that estimates of genetic correlation between $\mathrm{CC}$ and $\mathrm{OP}$ trials may suffer from downward bias due to confounding with $\mathrm{G} \times \mathrm{E}$ interactions. However, since the same genetic material was established at several sites it was possible to account for such a bias by partitioning correlation estimates from a restricted multivariate analysis into non-confounded genetic correlation factors across crossing designs and environments (Equations 3 \& 4).

\section{$\mathrm{OP}-\mathrm{CC}$ differences in genetic varia- tion}

Individual estimates of $\hat{C V}$ and heritability in OP trials of Scots pine and Norway spruce varied considerably in relation to the corresponding $\mathrm{CC}$ trial estimates (Table 2), but OP estimates were not consistently larger than the corresponding $\mathrm{CC}$ estimates and the parameters were never significantly different from each other. The differences between $\mathrm{OP}$ and $\mathrm{CC}$ estimates of $\hat{C V} V_{A}$ and heritability could therefore be explained by estimation errors and the limited number of parents studied as well as by violation of the true half-sib assumption. When taken as an average across sites, OP estimates of heritability were $29 \%$ and $1 \%$ greater than the corresponding CC estimates for Scots pine and Norway spruce respectively. The seemingly larger average overestimation observed for Scots pine should be interpreted with caution as heritability estimates per se were very low and the OP overestimation of heritability was thus only 0.02 in the absolute sense.

These results agree with the general observations made by Scots pine and Norway spruce tree breeders that OP trial estimates of heritability tend to be similar to those of CC trials (reported for Scots pine by Hannrup et al., 2008), although it should be cautioned that comparisons between progeny trials generated by different sets of parents are very difficult. The results of this study are also consistent with earlier molecular marker genotyping studies reporting that OP progeny from Scots pine and Norway spruce seed orchards were almost exclusively generated by outcrossing (Burczyk et al., 2004; Muona and Harju, 1989; Pakkanen et al., 2000; Shimono et al., 2011; Torimaru et al., 2012) thereby excluding one important source of genetic parameter estimation bias.

For other conifer species such as maritime pine, Nordmann fir and red spruce similar marker studies also reported outcrossing ratios in OP progeny to be close to one (Doerksen and Herbinger, 2010; Gaspar et al., 2009; Hansen and Nielsen, 2010), and furthermore reported OP half-sib coancestry coefficients to be in the range $0.130-0.145$ implying an additive genetic variance overestimation by, at most $16 \%$, given that OP half-sibs had been assumed to be true half-sibs. Some investigators included paternity data using molecular markers when estimating heritabilities of OP progeny and compared these estimates to the corresponding estimates where fathers were treated as unknown, a situation resembling the comparison between OP and CC progeny in this study. Such an investigation 
Table 5: Additive genetic correlations constrained to be equal: $\left(\hat{r}_{a}\right)$ across sites but within crossing design, $\left(\hat{r}_{b}\right)$ within sites but across crossing designs, $\left(\hat{r}_{c}\right)$ across sites and crossing designs; and the adjusted unbiased additive genetic correlations: $\left(\hat{r}_{T}\right)$ between crossing designs, $\left(\hat{r}_{S}\right)$ across sites and $\left(\hat{r}_{S T}\right)$ across trials within sites, for tree height (H1) and diameter at breast height (D1, D2) in Scots pine and Norway spruce

\begin{tabular}{lccccc}
\hline & \multicolumn{2}{c}{ Scots pine } & & \multicolumn{2}{c}{ Norway spruce } \\
\cline { 2 - 3 } \cline { 5 - 6 } Correlations & $\mathrm{H} 1$ & $\mathrm{D} 1$ & $\mathrm{H} 1$ & $\mathrm{D} 2$ \\
\hline \multicolumn{2}{l}{ Constrained additive genetic correlations } \\
$\hat{r}_{a}=\hat{r}_{S} \cdot \hat{r}_{S T}$ & $0.95(0.10)$ & $\mathbf{0 . 8 3}(\mathbf{0 . 1 3})$ & & $\mathbf{0 . 8 3}(\mathbf{0 . 0 5})$ & $\mathbf{0 . 8 3}(\mathbf{0 . 0 5})$ \\
$\hat{r}_{b}=\hat{r}_{T} \cdot \hat{r}_{S T}$ & $1.06(0.12)$ & $1.05(0.17)$ & & $\mathbf{0 . 6 8}(\mathbf{0 . 1 0})$ & $\mathbf{0 . 7 2}(\mathbf{0 . 0 9})$ \\
$\hat{r}_{c}=\hat{r}_{T} \cdot \hat{r}_{S} \cdot \hat{r}_{S T}$ & $\mathbf{0 . 8 3}(\mathbf{0 . 1 2})$ & $\mathbf{0 . 7 3}(\mathbf{0 . 1 7})$ & & $\mathbf{0 . 6 1}(\mathbf{0 . 1 1})$ & $\mathbf{0 . 6 4}(\mathbf{0 . 1 0})$ \\
\hline
\end{tabular}

Adjusted additive genetic correlations

$\begin{array}{lcccc}\mathrm{CC}-\mathrm{OP}, \hat{r}_{T} & 0.87 & 0.88 & \mathbf{0 . 7 4} & \mathbf{0 . 7 7} \\ \text { Across sites, } \hat{r}_{S} & \mathbf{0 . 7 8} & \mathbf{0 . 6 9} & 0.90 & 0.89 \\ \text { Within site, } \hat{r}_{S T} & 1.22 & 1.20 & 0.92 & 0.94\end{array}$

Note: Standard errors are given in parentheses and correlation estimates significantly lower than unity $(p<0.05)$ are given in bold.

in western larch (El-Kassaby et al., 2011) found, in contrast to our results, that the heritability for tree height estimated by using the half-sib assumption was over twice as large as the corresponding estimate utilizing paternity information. The OP progeny of the latter study was however generated by a limited number of mothers (15) located in a seed orchard that comprised a greater number of parents (41). Consequently, the addition of paternity data increased the number of parents investigated considerably and the differences between heritability estimates utilizing and not utilizing paternity information may therefore have been due to a sample effect as well as the violation of the halfsib assumption. Hansen and Nielsen (2010) investigated several quantitative traits measured on $\mathrm{OP}$ progenies of 23 Nordmann fir parents (both fathers and mothers) and observed, in results similar to those reported here, that individual heritabilities estimated without paternity information could be considerably larger as well as smaller in comparison with their respective estimates including paternity.

Although the observations made by us and by others do not rule out the possibility that heritability and $\hat{C V}$ a may be overestimated to some extent, the results from this study nevertheless imply that systematic overestimation of these parameters for Norway spruce and Scots pine OP progenies due to violation of the true half-sib assumption is minor.

\section{Genetic correlations between OP and CC trials}

Genetic correlations between Scots pine OP and $\mathrm{CC}$ trials were generally very high and were close to unity (about 0.9) when adjusted for confounding with $\mathrm{G} \times \mathrm{E}$ interactions (Tables 3 and 5), but should nonetheless be interpreted with caution because the estimation errors were very large due to the small number of parents investigated and to the consistently low additive genetic variances observed (Table 2). The genetic correlation estimates between Norway spruce OP and CC trials were also high (Table 4), approximately 0.75 when adjusted for $\mathrm{G} \times \mathrm{E}$ interactions, but were nonetheless significantly lower than unity. Despite the indication that OP progeny breeding values for Norway spruce may be biased to some extent, the high genetic correlations between $\mathrm{CC}$ and $\mathrm{OP}$ trials still suggest that OP breeding values for Norway spruce and Scots pine can be as reliable as those estimated from CC trials provided that a sufficiently high number of OP progenies are measured.

It should be noted that the flowering of Norway spruce is known to be irregular and sporadic and that male reproductive success is more uneven among Norway spruce individuals (Burczyk et al., 2004; Shimono et al., 2011) than among Scots pines (Torimaru et al., 2012). Consequently, it is possible 
that the Norway spruce mothers were fertilized by pollen of different and restricted sets of fathers with different average breeding values, thereby influencing the breeding values of the $\mathrm{OP}$ progeny and decreasing the CC-OP genetic correlation. Under such conditions, specific full-sib family effects originating from the dominance genetic variation may also bias OP based breeding values because certain full-sib families could be overrepresented within OP progeny.

To our knowledge, no other studies on conifers have estimated genetic correlations between the results of $\mathrm{OP}$ and $\mathrm{CC}$ trials on the same genetic material. However correlations between breeding values predicted using a simple half-sib family model and breeding values predicted by a full-sib family model were estimated in the earlier mentioned studies which used molecular markers to identify fathers (Doerksen and Herbinger, 2010; El-Kassaby et al., 2011; Hansen and Nielsen, 2010). The correlation estimates from those studies were all moderate to high (0.44-0.97), and thus largely consistent with the results of this study. Overall, the high genetic OP-CC correlations suggests that parental ranking using OP progenies is quite reliable in comparison to using full-sib trials and that the small discrepancies (found in Norway spruce) give very little cause for concern.

\section{Comparisons of studies on spruce, pine and Eucalyptus spp.}

For some Eucalypt tree species such as Eucalyptus regnans F. Muell., Eucalyptus globulus ssp. globulus Labill. and Eucalyptus nitens (Deane \& Maiden) Maiden, comparisons of genetic parameters estimated from $\mathrm{OP}$ and $\mathrm{CC}$ progenies of the same genetic origin have been published (e.g. Costa e Silva et al., 2010; Griffin and Cotterill, 1987; Hodge et al., 1996; Jordan et al., 1999). In contrast to observations made on spruces and pines, additive genetic variances estimated from Eucalypt OP progenies were frequently four times as large as additive genetic variances estimated from progenies generated by controlled crosses given that the classical assumption of true half-sibs was made. The same investigators also found that genetic correlations between progeny generated by open pollination and controlled crossing were frequently poor (they could be as low as -0.46). Given these re- sults, it is not surprising that OP progeny of the Eucalypt species referred to above were considered unsuitable for progeny testing, while in contrast, for some conifers OP progenies appear to be as reliable as those generated from controlled crosses.

One important factor that could explain the different conclusions drawn from Eucalypts and from conifers is that open pollination in Eucalypts tends to produce a substantial percentage of severely inbred, but viable, progenies due to self fertilization (Borralho, 1994; Hardner and Potts, 1997). In several conifer species, Scots pine and Norway spruce being no exception, such selfed progenies have been eliminated already at the seed stage due to early and extreme inbreeding depression (Kärkkäinen and Savolainen, 1993; Koski, 1971; Williams, 2007). Furthermore, eucalypts are naturally insect pollinated and paternal reproductive success may therefore be highly uneven.

\section{Practical implications and conclusions}

Heritability and $C V_{A}$ estimated from progeny of Norway spruce and Scots pine generated by open pollination were not significantly different from those of progeny generated by controlled crosses and consequently large overestimations of these parameters due to the assumption of true half-sibs appear very unlikely in Norway spruce and Scots pine. Genetic correlations between OP and CC trials were furthermore very close to unity in Scots pine and high (approximately 0.75) for Norway spruce suggesting that parent breeding values based on OP progenies of these species should be fairly unbiased.

With respect to the estimation of additive genetic parameters and selection of superior parents (backward selection), the results of this study consequently suggest that progeny testing using open pollination are fully adequate and that the benefits of using controlled crossing designs or paternity assignment would be small. However, efficient selection of progenies (forward selection) and controlling the buildup of coancestry require progeny trials with full pedigree information. In this respect the assignment of fathers to OP progeny (or of any progeny) by molecular marker genotyping, a strategy often called breeding without breeding (ElKassaby and Lstibưrek, 2009) offer an alternative to controlled cross designs.

Estimation errors of the genetic parameters of 
this study were generally considerable. Future research should therefore use molecular marker assisted paternity assignment in progeny trials generated from a larger set of parents than that of the current study in order to increase the precision of genetic parameter estimates to the point that also minor overestimation of $C V_{A}$ and heritability could be detected and to better confirm the OP-CC genetic correlation estimates observed in this study.

\section{Acknowledgements}

This study was financed by the Swedish Forest Tree Breeding Association. The authors also acknowledge the three anonymous reviewers who contributed to the improvement of this manuscript. This study was financed by the Swedish Forest Tree Breeding Association, grant number 99 (2003).

\section{References}

Askew, G.R. and El-Kassaby, Y.A. (1994) Estimation of relationship coefficients among progeny derived from wind-pollinated orchard seeds. Theor. Appl. Genet. 88, 267-272

Borralho, N.M.G. (1994) Heterogeneous selfing rates and dominance effects in estimating heritabilities from open-pollinated progeny. Can. J. For. Res. 24, 1079-1082

Burczyk, J., Lewandowski, A. and Chalupka, W. (2004) Local pollen dispersal and distant gene flow in Norway spruce (Picea abies [L.] Karst.). For. Ecol. Manag. 197, 39-48

Burdon, R.D. (1977) Genetic correlation as a concept for studying genotype-environment interaction in forest tree breeding. Silvae Genet. 26(56), 168-175

Costa e Silva, J., Hardner, C.M. and Potts, B.M. (2010) Genetic variation and parental performance under inbreeding for growth in Eucalyptus globulus. Ann. For. Sci. 67, 606p1-606p8

Doerksen, T.K. and Herbinger, C.M. (2010) Impact of reconstructed pedigrees on progeny-test breeding values in red spruce. Tree Genet. Genomes 6 , $591-600$
El-Kassaby, Y.A., Cappa, E.P., Liewlaksaneeyanawin, C., Klápště, J. and Lstibůrek, M. (2011) Breeding without breeding: Is a complete pedigree necessary for efficient breeding? PLoS One 6(10), e25737

El-Kassaby, Y.A. and Lstibůrek, M. (2009) Breeding without breeding. Genet. Res. Camb. 91, $111-120$

Falconer, D.S. and Mackay, T.F.C. (1996) Introduction to Quantitative Genetics. 4 ed., Pearson, Prentice Hall

Gaspar, M.J., de Lucas, A.I., Alia, R., Pinto Paiva, J.A., Hidalgo, E., Louzada, J.L., Almeida, M.H. and González-Martínez, S.C. (2009) Use of molecular markers for estimating breeding parameters: a case study in a Pinus pinaster Ait. progeny trial. Tree Genet. Genomes 5, 609-616

Gilmour, A.R., Gogel, B.J., Cullis, B.R. and Thompson, R. (2009) ASReml User Guide. VSN International Ltd, Hemel Hempstead, HP1 1ES, UK, 3rd ed.

Griffin, A.R. and Cotterill, P.P. (1987) Genetic variation in growth of outcrossed, selfed and open-pollinated progenies of Eucalyptus regnans and some implication for breeding strategy. Silvae Genet. 37(3-4), 124-131

Hannrup, B., Jansson, G. and Danell, Ö. (2008) Genotype by environment interaction in Pinus sylvestris L. in southern Sweden. Silvae Genet. 57(6), 306-311

Hansen, O.K. and Nielsen, U.B. (2010) Microsatellites used to establish full pedigree in a half-sib trial and correlation between number of male strobili and paternal success. Ann. For. Sci. 67, 703p1-703p10

Hardner, C.M. and Potts, B.M. (1997) Postdispersal selection following mixed mating in Eucalyptus regnans. Evolution 51(1), 103-111

Hodge, G.R., Volker, P.W., Potts, B.M. and Owen, J.W. (1996) A comparison of genetic information from open-pollinated and control-pollinated progeny tests in two eucalypt species. Theor. Appl. Genet. 92, 53-63 
Jordan, G.J., Potts, B.M. and Wiltshire, R.J.E. (1999) Strong, independent, quantitative genetic control of the timing of vegetative phase change and first flowering in Eucalyptus globulus ssp. globulus (Tasmanian Blue Gum). Heredity 83, 179-187

Kärkkäinen, K. and Savolainen, O. (1993) The degree of early inbreeding depression determines the selfing rate at the seed stage: model and results from Pinus sylvestris (Scots pine). Heredity $71,160-166$

Kempthorne, O. and Curnow, R.N. (1961) The partial diallel cross. Biometrics 17(2), 229-250

Koski, V. (1971) Embryonic lethals of Picea abies and Pinus sylvestris. Commun. Inst. For. Fenn. $75,1-30$

Muona, O. and Harju, A. (1989) Effective population sizes, genetic variability, and mating system in natural stands and seed orchards of Pinus sylvestris. Silvae Genet. 38(5-6), 221-228

Pakkanen, A., Nikkanen, T. and Pulkkinen, P. (2000) Annual variation in pollen contamination and outcrossing in a Picea abies seed orchard. Scand. J. For. Res. 15, 399-404

Self, S.G. and Liang, K.Y. (1987) Asymptotic properties of maximum likelihood estimators and likelihood ratio tests under nonstandard conditions. J. Am. Stat. Ass. 82(398), 605-610

Shimono, A., Wang, X.R., Torimaru, T., Lindgren, D. and Karlsson, B. (2011) Spatial variation in local pollen flow and mating success in a Picea abies clone archive and their implications for a novel "breeding without breeding" strategy. Tree Genet. Genomes 7(3), 499-509

Squillace, A.E. (1974) Average genetic correlations among offspring from open-pollinated forest trees. Silvae Genet. 23(5), 149-156

Torimaru, T., Wennström, U., Lindgren, D. and Wang, X.R. (2012) Effects of male fecundity, interindividual distance and anisotropic pollen dispersal on mating success in a Scots pine (Pinus sylvestris) seed orchard. Heredity 108, 312-321
Williams, C.G. (2007) Re-thinking the embryo lethal system within the Pinaceae. Can. J. Bot. $85,667-677$ 